\title{
Library Building Costs
}

The data presently being collected concerning costs of academic library buildings and their furnishings and equipment are frequently so incomparable as to be almost useless. The principles upon which these data should be determined are enumerated, and a sample report form is laid out. The paper proposes that, until an appropriate ACRL body settles upon a better instrument for collecting data on building costs, the report form given here be used.

$\mathrm{L}$

IBRARIANS WHO ARE INVOLVED in planning libraries are naturally interested in costs and seek to learn what they can from the experience of others as an aid in working out their own building construction budgets. Statistics of library building costs have been gathered for many years and made available in various library publications. A serious problem arises in connection with them: the figures reported are too rarely comparable and so far less useful than they should be. This is true also of statistics which deal with the size of library collections in terms of volumes or volumes and pamphlets. In both cases-building costs and collection statistics-libraries have been unable to agree on principles for the computations.

The complications in connection with the size of collections are comparatively simple; they involve primarily three questions: How are pamphlets counted, and must they be bound and have a certain number of pages if they are to be included as volumes? Must material be cataloged in full to be included? Should a physical piece or a bibliographical unit count be used?

Dr. Metcalf is Librarian Emeritus of Harvard University.
The complications in connection with building costs are more numerous and are equally difficult. They arise from a lack of a general agreement on the items that should be included, and also on five other factors which make the reported costs difficult to compare, even if agreement is reached on what should be included. These factors are:

1. Costs differ from one place to another because of variations in wage rates, in the efficiency of labor, in the local availability of mechanical building aids, and in the freight rates for materials brought to the site from a distance.

2 . Costs may be influenced by the economic conditions in the construction business at the time the bids are taken. There may be a difference of as much as 5 per cent within a few months because of this factor alone.

3. Costs may differ with the time of year bids are taken. A contractor will sometimes bid lower at the beginning of his financial year until his projected work quota is filled. In northern climates open construction in winter will increase costs.

4. Costs differ widely because the quality of construction and materials called for in the drawings and specifications differ. This has a very great effect 
on over-all costs and must always be kept in mind in making comparisons. This is the greatest single factor.

5. Costs may differ because the cost per square foot of floor space is often affected by the intensity of space utilization. If space is well utilized, the project cost per square foot goes up, but the cost per volume stored and reader accommodated should go down. Cubage, as well as square footage, also affects cost. When ceiling heights are over-generous or when they have been reduced below practical minimums, costs are likely to be increased.

No one of these five factors can be measured precisely, but the basic costs per square foot for the construction of floor space generally can be. And, certainly, an accurate record of the expenditures required to house satisfactorily a given number of volumes and readers can be useful and should be made available if possible.

Building costs, if the term is broadly interpreted, can be more completely reported and more equitably compared to others if they are divided into the budget groupings which are outlined and briefly discussed below.

1. The cost of the basic building contract, including fixed or built-in equipment attached to the building and also the book stacks, but not including other loose furniture and equipment. It is desirable to record separate figures for the five following items, which are generally subcontracts: heating and ventilating, plumbing, lighting and other electrical work, elevators and lifts, and metal stack shelving, whether it is multi-tier or freestanding.

2. The cost of loose furniture and equipment, except metal shelving.

3. Professional fees for architects, engineers, and consultants.

4. Expenditures relating to the site, including the cost of land if it must be acquired, and of surveys and investiga- tion of subsoil conditions; the cost of the site development, such as the expenditures required to bring in services, that is, water, sewer, electric current, steam and chilled water; costs resulting from unusual foundation conditions; and the cost of landscaping, preparation of parking areas, and so forth. These expenditures will rarely be directly comparable with those for other libraries, but they are of interest and can properly be recorded separately. If possible, the report can usefully break these down into subheadings, but they should at least be summarized under Site.

5. The owner's expenditures in connection with the planning and construction of the building, such as costs involved in visiting libraries and for other planning team expenses; costs of advertising and the printing of specifications and working drawings not included in the architectural fees; financing charges for raising or borrowing money; salary for the clerk of works who is often called the resident engineer, and the cost of fire and liability insurance during construction.

6. Costs involved in occupying the new building, including the cost of moving; of extra staff during the move and the "shaking down" period; and of the dedication and other ceremonies.

The more important groups for our purpose are 1,2 , and 3 , but the others4 to 6 -are of interest and worth recording, although they are rarely comparable. In any case, they should be separated from other costs.

The author of this article would be the first to concede that this is not a definitive statement, and it will not be difficult to find flaws in it, but he proposes that academic libraries use the following form until something better can be evolved. He also suggests that an ACRL committee be appointed to receive criticisms and comments and to prepare an improved form later. 
CRL invites academic librarians who open new buildings to copy and fill out the report form proposed here by $\mathrm{Dr}$. Metcalf and send it to $\mathrm{Mr}$. Theodore Samore, USOE, and to the editors of $C R L$. Efforts will be made periodically to coordinate and tabulate the reports received.

\section{Cost Data Form for Library Construction}

1. Main construction contract cost, excluding loose furniture and equipment costs reported in 2 below, but including fixed and built-in equipment and main book stacks, whether free-standing or multi-tier. Please state in a note what fixed and built-in equipment is included.

a. Heating and ventilation. Please state in a note the extent of the air conditioning, that is, heating, cooling, humidification, dehumidification, filtering, and forced ventilation that has been used; whether the entire building or only special parts of it are included, and what part of the ventilation apparatus is in the library.

b. Plumbing.

c. Lighting and other electrical work.

d. Elevators and lifts.

e. Book stacks. Exclude book cases in reading areas included in 2 below.

f. Cabinet work, service desks, and built-in equipment included in main building contract.

g. All other items in main construction contract.

Total for main construction contract.

Cost
2. Loose furniture and

No.

Cost equipment. Please give number of units and cost for each group, if it is available.

a. Wood book cases in offices, studies, and in reading areas if not built in and included in $1 \mathrm{~g}$ above. Record in terms of standard size single-faced sections, $3^{\prime}$ wide by 7 ${ }^{\prime \prime \prime}{ }^{\prime \prime}$ high.

b. Side chairs.

c. Armchairs, excluding lounge chairs.

d. Lounge chairs.

e. Carrels. Include under carrels, individual accommodations provided at tables for more than one if the reader is cut off from his neighbors by partitions. (If carrels are built in and included in 1 , please state in a note.)

f. Tables for more than one without partitions.

g. Catalog cabinets in terms of trays. Specify in a note the number of trays high in each cabinet and over-all depth of trays.

h. Office desks.

i. Library mechanical equipment, such as computers, electronic devices, audiovisual apparatus, and so forth.

j. Miscellaneous loose equipment.

Total for loose furniture and equipment.

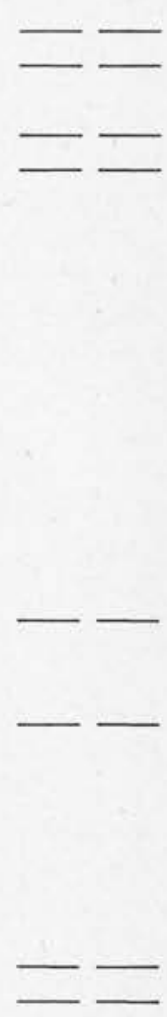


Total for 1 and 2 .

3. Fees for architects and consultants of all kinds, including engineers, designers, and decorators.

Total for items 1-3.

Cost

4. Site and Site Development.

a. Cost of land if it did not already belong to the institution. If no purchase was involved, state "none."

b. Cost of site development.

This should include the cost of surveys, investigation of subsoil conditions and of borings, any increase in costs occasioned by the need for special foundations, such as piles and caissons instead of regular footings, and the cost of rock excavations.

c. Cost of bringing in services, that is, water, sewer, electric current and of steam and chilled water if the institution has central heating and cooling plants.

d. Did the building make necessary a new central heating plant or a new cooling plant for the institution? Yes- NoIf yes, please note amount, if any, that was charged against the library.

e. Cost of landscaping, grading, seeding, preparation of parking areas, and so forth, including work done by the owner's staff.

Frequently many of the costs in $a-e$ are included in the main building contract. If possible, obtain separate estimates for them and subtract the total from the figure used in 1 above.

Total for site and site development.
5. Owner's expenditures in connection with the planning process.

a. Travel costs involved in visiting libraries by members of the planning team, consultants and architects, and other planning team expenditures.

b. Cost of advertising and printing of specifications and working drawings not included in architectural fees, and of fire and liability insurance during construction.

c. Financing charges for raising or borrowing money.

d. Clerk of works, or resident engineer.

Total for owner's expenditures.

6. Costs involved in occupying the new building.

a. Actual cost of the shift of books and equipment.

b. Cost of extra library staff employed during the move and the shaking-down period. ( $a$ and $b$ should not overlap.)

c. Cost of cornerstone laying, dedication, and other ceremonies.

\section{Total for occupation costs.}

Total for 4-6.

Grand total for project costs, including items 1 through 6 .

\section{Contingency Fund Arrangements}

Did your building budget as originally set up include:

1. A contingency fund for unexpected expenditures in the basic contract? Yes- $\mathrm{No}-$.

Was this reduced during the planning period? Yes- No- Please give details in a note.

How much of it was finally used?

2. A separate item for furniture and equipment? Yes- Noit?

If one was included, how much was 
Was it estimated on the basis of a percentage of the building cost or in some other way?

How much of it was used?

3. A provision in the original budget for escalation of costs due to a possible increase in wage rates or to other costs stemming from intlation in case construction was delayed beyond the time it had been hoped the contract could be let? Yes- NoPlease give details in a note.

\section{General Questions}

1. Does the building enclose any space remaining unfinished at this time? Yes- No- If yes, how many square feet?

2. Do any major portions of the equipment and furniture planned for the building remain to be purchased later?

3. Names of architectural firm, contractor, and consultants?

4. Date of occupation of the new building.

\section{SUMmary Data}

1. Gross square footage in the building.

2. Net or assignable square footage.

(Net square footage should exclude that used for walls and partitions, stairwells, and other areas required for vertical transportation, for entrances, vestibules, and lobbies, for toilets and service closets, for mechanical areas, and for corridors used for corridors only. If corridors are used for shelving or exhibitions, exclude one half of total.)
3. Cost per gross square foot of main building construction contract.

4. Gross cubage of main building construction.

5. Cost per cubic foot of main building construction contract.

6. Clear floor heights. Specify for each in a note if they vary from floor to floor.

7. Finished ceiling to finished floor thickness. Specify for each if they vary from floor to floor.

\section{Number of Seating Accommodations}

1. At regular library tables.

2. Individual seating at tables for one, in carrels, or in other petitioned-off areas.

3 . Lounge seating.

4. Faculty or graduate student studies that can be locked.

Total seating accommodations in 1-4 above.

Note: Do not include in the seating that available in seminars, classrooms, etc., or for the staff, or for the public at control desks, but state in a note the number of seats in seminars and classrooms.

\section{VOLUME CAPACITY ${ }^{\circ}$}

1. In main stack area.

2. In special storage areas.

3 . In reading areas.

- Please report volume capacity on the basis of 125 for each standard single-faced, $3^{\prime}$ wide, $7 \frac{1}{\prime \prime}{ }^{\prime}$ high section. If volume capacity was figured on another basis, please report in a note.

\section{Slavic, East European Directory}

The Slavic and East European Subsection, Subject Specialists Section of ACRL is compiling a directory of librarians, archivists, and information specialists in the field of Slavic and East European studies. To give the directory maximum reference value, it is expected to include subject, area, or language specialists engaged in library, bibliographic, or documentation activity, and graduate library school students with competence in the field of Slavic and East European studies.

Interested persons should write for questionnaires to Mr. Peter Goy, Directory of Slavic Librarians, c/o City College Library, Room 201A, New York, N.Y. 10031. 